\title{
Research on Matching Degree of Resources and Capabilities of Enterprise Transformation Based on the Spatial Points Distance
}

\author{
Jifa Wang, Hang Chen ${ }^{*}$ and Haiyan Ao
}

School of management, Shenyang University of Technology, Shenyang, Liaoning, 110870, China

\begin{abstract}
The purpose of enterprise transformation is to obtain the sustainable competitive advantage, and the strong reflection of sustainable competitive advantage is the effective transformation and matching of resources and capabilities. In this paper, the matching relationship between resources and capabilities of enterprise transformation system is analyzed, and the evaluating index system for the resources and capabilities of enterprise transformation system are developed. Using the concept of 4 dimensional space distances between 2 points, the model for computing the matching degree between the resources and capabilities of enterprise transformation system is constructed. Finally, through case analysis to the transformation of $\mathrm{K}$ enterprise concluded the influence degree of the matching degree of resources and capabilities of enterprise transformation system to enterprise transformation.
\end{abstract}

Keywords: Enterprise Transformation; Sustainable Competitive Advantage; Resources and Capabilities; Matching Degree

\section{INTRODUCTION}

At present, with the critical period of China's economy into the economic transformation and industrial restructuring, we clearly recognize that, implementation of enterprise transformation, accelerate industrial upgrading, the implementation of enterprise strategic transition, it is decided whether the enterprise revitalized, and achieve a major problem of regional economic revitalization [1]. At the same time, enterprise transformation is the full use of their own internal resources based on the ability of the enterprise, is to adapt to changes in the external environment, competitive advantages to maximize as the goal, the strategic behavior of economic growth mode transformation of enterprises. Therefore, enterprises successful transition is mainly manifested in the full utilization of resources and effective play of capabilities $[2,3]$. This article through the matching relationship between resources and capabilities, to the enterprise competitive advantage and the role of both, to calculate the matching degree of resource and ability of enterprise transformation in the system, and then found the problems of resource management and ability improvement of enterprise transformation system.

\section{THE MATCHING RELATIONSHIP OF ENTER- PRISE RESOURCE AND CAPABILITIES IN THE SYSTEM TRABSFORMATION}

From the analysis of the logic of material, resource is the basis of business survival, is an important part of enterprise. Resource plays an indispensable role in the survival and development of enterprises, it is the basic unit of analysis of enterprise resource management theory, is the starting point of the research on enterprise resource theory [4]. Therefore, the resources in the system transformation of the research of enterprise is mainly analyzes the effect of resource on the enterprise competitive advantage, that is to study the influence on the transformation of the enterprise's competitive advantage and core competence from the human resources, technical resources, economy and environmental resources and goodwill resources in four aspects. First of all, the human resource is the combination of human capital of enterprise, has come from the unique enterprise culture, history and the complexity of society is difficult to imitate and scarcity. Secondly, for the technical resources, it is the source of all the interests of the enterprise, is a kind of resources by the radiation information of knowledge resources. At the same time, technology resources are constantly in change process of enterprise transformation system, and it's this in order to adapt to the external environment and constantly revised, and gradually improve the process and to enhance the dynamic capabilities for enterprises to enhance competitive advantage brought motive force, to provide the powerful basis for the successful transformation of enterprises [5]. Once again, not all of the factors on the economic of environment and resources have an impact on the sustainable competitive advantage, they are the vast majority of factors of knowledge for the development of enterprises to provide the premise, but some factors such as the professional with the upstream and downstream industry chain, the development of industry to clear and clear target market of these factors will make the enterprise have special competitive advantage. Thus it can be seen that the economic environment has indirect effect of sustainable competitive advantage through the practice of enterprises [6]. Finally, the goodwill resources can bring benefits to enterprises, including the brand, product quality, durability and reliability of the recognition, customer and supplier credit. 
The ability of enterprise transformation in the system, which reflects the internal characteristics of enterprises, including the core competence to establish competitive advantage for the enterprise and enterprises need to engage in normal production and operation activities of general ability. Therefore, for transformation of enterprises, the factors of reflect the ability main performance the technology innovation ability, marketing ability, management ability and the ability of strategic management. Among them, the technology innovation is mainly refers to the introduction of advanced technology, development and utilization, it is directly related to the product [7]. And the enterprise sustainable marketing competence is effective points out the connotation of marketing is marketing culture, marketing ability and marketing ability of learning; The ability of organization and management is refers to in the dynamic and complex environment, the enterprise to produce the new resource structure through the combination of resources, in order to respond to changes in the market strategic organizational process. The enterprise strategic management ability development, implementation and evaluation of the organization's strategic ability to achieve its goals [8].

Thus it can be seen, resources and ability of enterprise transformation system is transformed into each other, mutual matching. Resources to the ability of the transformation are mainly reflected in: first, there is a complementary relationship between resources and capabilities, the two are complementary to each other. At the same time, forms of resources in the process of enterprise restructuring is a static stock, and ability is a kind of kinetic energy, the relationship between the two is the performance of enterprises of a certain amount of resources to provide a potential for enterprises to achieve high competitiveness, which is the transformation of enterprises have competitive prerequisite [9]. Secondly, the enterprise ability is a reflection of inherent in the use performance of the existing various resources of a combination, therefore, a more systematic, combination. Again, combined with the ability and resources to produce a competitive advantage, the competitiveness is the result of the interaction of resources and capabilities.
Finally, the main purpose of the enterprise ability is to improve the conversion efficiency of the enterprise resource system. And the ability of resource to promote the accumulation of the main performance is: first, the ability to directly promote the accumulation of resources. Secondly, the effective use of ability in some extent could improve the utilization rate of resources, namely, when using ability, pass through certain channels and ways, indirectly increase the resources information that matches the ability [10].

Therefore, resources and ability of enterprise transformation in the system refers to the resource intensity and ability level consistent with each other, each other to strengthen. From the analysis we can see that the including two levels (Fig. 1): the total matching, namely the overall degree of matching resources and capabilities; component matching, namely the matching degree of each subsystem of resources and ability system:

\section{ANALYSIS CONSTRUCTION OF EVALUATION INDEX SYSTEM OF THE RESOURCES INTENSITY AND ABILITY LEVEL IN ENTERPRISE TRANS- FORMATION SYSTEM}

\subsection{The Evaluation Index System of Resources Intensity and Ability Level}

In order to comprehensive analysis the matching degree of resource and ability of enterprise transformation system, fully embodies the combination of the two mutual aid, in this paper, on the basis of the above analysis, that the resources of the enterprise transformation system composed of technical resources, human resources, economic resources and capital resources. While capacity by technology innovation ability, marketing ability, management ability and strategic management capability, and according to the specific content of the four dimensions, in accordance with the scientific, comprehensive and systematic principles in the construction of the resources and capabilities of enterprise transformation in the system of evaluation index system, respectively, as shown in Tables $\mathbf{1}, \mathbf{2}$.

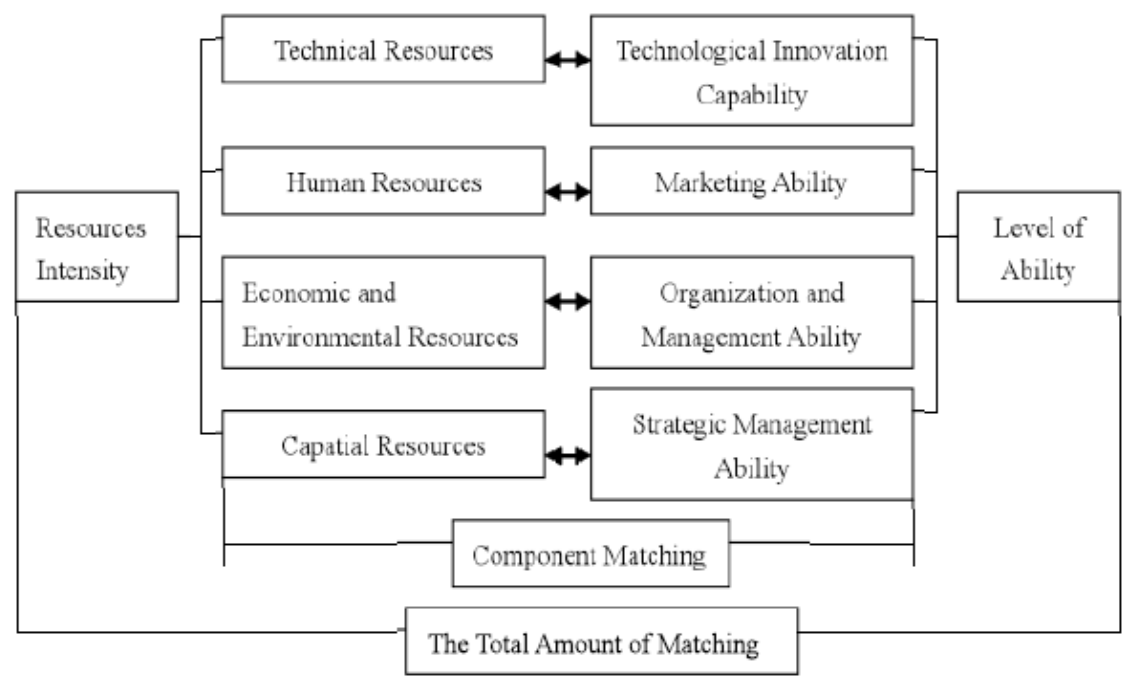

Fig. (1). The matching hierarchical graph of resources and ability of enterprise transformation system. 
Table 1. The evaluation index system and weight of resource intensity.

\begin{tabular}{|c|c|c|}
\hline The Criteria Layer & The Index Layer & Weight \\
\hline \multirow[t]{2}{*}{ Technical resources $\left(A_{1}\right)$} & $\begin{array}{l}\text { Advanced technical equip- } \\
\operatorname{ment}\left(\mathrm{A}_{11}\right)\end{array}$ & 0.47 \\
\hline & Patent ownership $\left(A_{12}\right)$ & 0.53 \\
\hline \multirow[t]{4}{*}{ Human resources $\left(\mathrm{A}_{2}\right)$} & $\begin{array}{c}\text { Management personnel } \\
\text { quality }\left(\mathrm{A}_{21}\right)\end{array}$ & 0.29 \\
\hline & Quality of employees $\left(\mathrm{A}_{22}\right)$ & 0.33 \\
\hline & $\begin{array}{l}\text { Patent personnel propor- } \\
\operatorname{tion}\left(\mathrm{A}_{23}\right)\end{array}$ & 0.13 \\
\hline & $\begin{array}{l}\text { Human resources develop- } \\
\text { ment and profit rate }\left(\mathrm{A}_{24}\right)\end{array}$ & 0.25 \\
\hline \multirow{3}{*}{$\begin{array}{l}\text { Economic and Envi- } \\
\text { ronmental re- } \\
\text { sources }\left(\mathrm{A}_{3}\right)\end{array}$} & Industry outlook $\left(\mathrm{A}_{31}\right)$ & 0.33 \\
\hline & $\begin{array}{l}\text { The prospect of the indus- } \\
\qquad \operatorname{try}\left(\mathrm{A}_{32}\right)\end{array}$ & 0.29 \\
\hline & $\begin{array}{c}\text { Superior geographical } \\
\text { location and resources }\left(\mathrm{A}_{33}\right)\end{array}$ & 0.38 \\
\hline \multirow[t]{4}{*}{ Capital resources $\left(\mathrm{A}_{4}\right)$} & Asset size $\left(\mathrm{A}_{41}\right)$ & 0.13 \\
\hline & Financing ability $\left(\mathrm{A}_{42}\right)$ & 0.22 \\
\hline & $\begin{array}{c}\text { Capital appreciation } \\
\operatorname{rate}\left(\mathrm{A}_{43}\right)\end{array}$ & 0.35 \\
\hline & $\begin{array}{l}\text { The rate of assets and li- } \\
\text { abilities }\left(\mathrm{A}_{44}\right)\end{array}$ & 0.30 \\
\hline
\end{tabular}

\subsection{Measure of Resource Strength and Ability Level}

(1) The Calculation of the weight

Usually to calculate the weight of indicators, the pure subjective weighting method is lack of accuracy and authority, to have a certain deviation. Therefore, this paper uses the entropy weighting method, through the analysis of the original data of the connection degree of each index and the corresponding evaluation index weights of each evaluation index system. The set of resources and capabilities on the 13 indicators and 5 grades, respectively, is not important, less important, important, more important, and very important. The specific weight calculation steps are as follows:

A decision matrix $D$ has $m$ evaluation index, $n$ grade:

$D=\left[\begin{array}{ccc}x_{11} & \cdots & x_{1 n} \\ \vdots & \ddots & \vdots \\ x_{m 1} & \cdots & x_{m n}\end{array}\right]$

(1) Through the decision matrix $D=\left(x_{i j}\right)_{m \times n}$ for $H_{i j}$ :

$H_{i j}=\frac{x_{i j}}{\sum_{i=1}^{m} x_{i j}} i=1,2, \cdots, m ; j=1,2, \cdots, n$
Table 2. The evaluation index system and weight of ability level.

\begin{tabular}{|c|c|c|}
\hline The Criteria Layer & The Index Layer & Weight \\
\hline \multirow[t]{3}{*}{$\begin{array}{l}\text { Technological innova- } \\
\text { tion capability }\left(\mathrm{B}_{1}\right)\end{array}$} & Technology devotion $\left(\mathrm{B}_{11}\right)$ & 0.32 \\
\hline & $\begin{array}{l}\text { Technology development } \\
\text { and utilization }\left(\mathrm{B}_{12}\right)\end{array}$ & 0.27 \\
\hline & $\begin{array}{l}\text { The rate of production re- } \\
\quad \operatorname{search}\left(\mathrm{B}_{13}\right)\end{array}$ & 0.41 \\
\hline \multirow[t]{3}{*}{ Marketing ability $\left(\mathrm{B}_{2}\right)$} & Product sales $\left(\mathrm{B}_{21}\right)$ & 0.32 \\
\hline & $\begin{array}{l}\text { Market development abil- } \\
\text { ity }\left(\mathrm{B}_{22}\right)\end{array}$ & 0.32 \\
\hline & $\begin{array}{l}\text { The brand construction } \\
\text { ability }\left(\mathrm{B}_{23}\right)\end{array}$ & 0.36 \\
\hline \multirow[t]{3}{*}{$\begin{array}{l}\text { Organization and man- } \\
\text { agement ability }\left(B_{3}\right)\end{array}$} & $\begin{array}{c}\text { Reasonable organization } \\
\text { structure }\left(\mathrm{B}_{31}\right)\end{array}$ & 0.34 \\
\hline & $\begin{array}{l}\text { Tissue expansion abil- } \\
\text { ity }\left(\mathrm{B}_{32}\right)\end{array}$ & 0.33 \\
\hline & $\begin{array}{l}\text { Not easy to imitate de- } \\
\text { gree }\left(\mathrm{B}_{33}\right)\end{array}$ & 0.33 \\
\hline \multirow[t]{4}{*}{$\begin{array}{l}\text { Strategic management } \\
\text { ability }\left(\mathrm{B}_{4}\right)\end{array}$} & Profit growth capacity $\left(\mathrm{B}_{41}\right)$ & 0.38 \\
\hline & $\begin{array}{c}\text { Capital expansion capac- } \\
\text { ity }\left(\mathrm{B}_{42}\right)\end{array}$ & 0.29 \\
\hline & $\begin{array}{c}\text { The ability of enterprise } \\
\text { development }\left(B_{43}\right)\end{array}$ & 0.19 \\
\hline & $\begin{array}{c}\text { The ability of management } \\
\text { innovation }\left(\mathrm{B}_{44}\right)\end{array}$ & 0.14 \\
\hline
\end{tabular}

(2) Calculate the entropy of each grade output:

$$
E_{j}=-\frac{1}{\ln m} \sum_{i=1}^{m} H_{i j} \ln H_{i j} j=1,2, \cdots, n
$$

Due to the $0 \leq H_{i j} \leq 1,0 \leq-\sum_{i=1}^{m} H_{i j} \ln H_{i j} \leq \ln m$,

so, $0 \leq E_{j} \leq 1 \quad j=1,2, \cdots, n$;

(3) Calculate the deviation degree:

$$
d_{j}=1-E_{j}, j=1,2, \cdots, n
$$

(4) Calculate the weight coefficient of every index $\omega_{j}$ :

$$
\omega_{j}=\frac{d_{j}}{\sum_{j=1}^{n} d_{j}}, 0 \leq \omega_{i} \leq 1, \sum_{i=1}^{m} \omega_{i}=1
$$

According to the calculation steps, put the transformation of enterprise resources and ability evaluation index $A_{i j}$ 
$(i=1,2,3,4 ; j=1,2, \cdots, n), B_{i j} \quad(i=1,2,3,4 ; j=1,2, \cdots, n)$ into the formula, obtained the weight of each index size of resource strength and ability level in enterprise transformation system, respectively $\alpha_{i j}, \beta_{i j}$.

\section{(2) Computing resources strength and ability level}

According to Delphi method to the transformation of the enterprise resources and ability of each evaluation index system of the $i$ subsystem in scoring, to get the score of resources and abilities of the $j$ index of the $i$ subsystem, they are $a_{i j}(j=1,2, \cdots, n), b_{i j}$

$(j=1,2, \cdots, m)$, so we can obtained the intensity of the resources and capabilities of enterprise transformation system of each subsystem, respectively $t_{i}$ and $c_{i}$ :

$t_{i}=\sum_{j=1}^{n} \alpha_{i j} a_{i j}, c_{i}=\sum_{j=1}^{n} \beta_{i j} b_{i j}$

is not the same, so we get 1986 and 1996, 2009 and 2011 data comparison.

\section{TO CONSTRUCT THE MATCHING DEGREE CALCULATION MODEL OF RESOURCES AND ABILITYOF ENTERPRISE TRANSFORMATION SYSTEM}

\section{(1) The total matching degree calculation model}

Due to resource and ability includes four dimensions, therefore, the concept of distance between 2 points in 4 dimensional space, is introduced in this paper, the strength of resources of each subsystem $\left(t_{1}, t_{2}, t_{3}, t_{4}\right)$ and the level of abilities of each subsystem $\left(c_{1}, c_{2}, c_{3}, c_{4}\right)$ as two points in space, namely, $T, C$ and use the distance between two points to define the matching degree of resource strength and ability level of the enterprise transformation system. At the same time, to establish the origin as the center, from the origin to the ability level point $\left(c_{1}, c_{2}, c_{3}, c_{4}\right)$ distance of spherical radius $r=\sqrt{\sum_{i=1}^{4} c_{i}^{2}}$, the resource intensity point $\left(t_{1}, t_{2}, t_{3}, t_{4}\right)$ in spherical within or outside to judge the resources strength shortage or surplus, as shown in Fig. (2).

Based on the above analysis, this paper gives the calculating model of the total matching of resource strength and ability level in enterprise transformation system:

$L_{T C}=\sqrt{\sum_{i=1}^{4}\left(t_{i}-c_{i}\right)^{2}}$

The definition of $s \in(0, r / 8)$ is threshold, usually determined by experts; in this paper the system of resource and capability has 4 subsystems in the enterprise transformation system, so $r / 8$ is taken as the upper limit. The smaller the value of $s$, the higher requirements of the overall strength of resources and ability level in enterprise transformation system, so we can draw the following criteria: (1) When $L_{T C} \leq s$, the overall strength of resource and the overall level of capacity are basic matching, and the smaller of $L_{T C}$, the better of total matching degree. (2) When $L_{T C}>s$, the overall strength of resource and the overall level of capacity in enterprise transformation system is not matching, and if $\sum_{i=1}^{4} c_{i}^{2}>s^{2}$, shows that the point of the overall strength of resources in the spherical outside, and the overall strength of resources is Surplus; if $\sum_{i=1}^{4} c_{i}^{2}<s^{2}$, shows that the point of the overall strength of resources in the spherical inside, and the overall strength of resources is shortage.

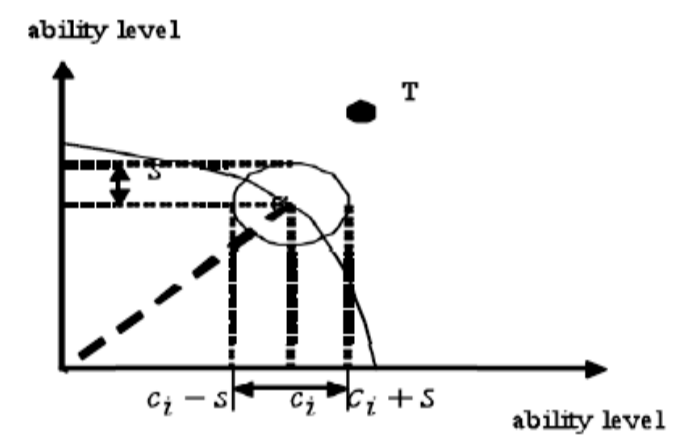

The range of resources subsystem of strength matching

Fig. (2). The matching diagram of the total amount and component of resources and capabilities in enterprise transformation system.

\section{(2) Component matching degree calculation model}

This paper based on the 2 points in 3 dimensional space of the comparison degree of projection on each dimension to evaluate the matching degree of each subsystem of resource strength and ability level. On the basis of the knowledge of geometry, when point

$T\left(t_{1}, t_{2}, t_{3}, t_{4}\right)$ and point $C\left(c_{1}, c_{2}, c_{3}, c_{4}\right)$ distance not greater than $s$, the range of $t_{i}$ is $\left[c_{i}-d, c_{i}+d\right](i=1,2,3)$, as shown in Fig. (2). The range of the matching intensity of the $i$ subsystem of resources system and the ability level is $\left[c_{i}-d, c_{i}+d\right]$, let $\varphi=\left|t_{i}-c_{i}\right|$, and $i=1,2,3$. The following components matching criterion: (1) When $c_{i}-d \leq t_{i} \leq c_{i}+d$, shows that the strength of $i$ subsystem of resources system and the ability level in enterprise transformation system is basic matching, and the smaller of $\varphi$, the higher the degree of matching, while $\varphi=0$, shows that the strength of $i$ subsystem of resources system and the ability level in enterprise transformation system is complete matching. (2) When $t_{i}<c_{i}-d$, shows that the strength of resource subsystem of enterprise transformation system is insufficient, and can not obtain provide effective protection to obtain the ability, at the same time the conversion of resources to the ability of the low efficiency. Therefore, enterprises should enhance the aggregation of resources, optimization of process, reasonable improve resource supply, in order to satisfy the dependence on resources, the resources and the ability to match. (3) When $t_{i}>c_{i}+d$, shows that the strength of resource subsystem of 
enterprise transformation system is far beyond the ability level limit, resources are not adequate to transformation, and reflects the reaction of resources. Therefore, enterprises should be appropriate to reduce the supply of resources, reduce the demand for resources, and meet the coordination between resources and capabilities, improving the matching degree of resource subsystem and ability level.

\section{THE CASE STUDY}

This article research matching degree of resources and ability in enterprise transformation system of enterprise K, measuring the index system based on the resource strength and ability level of enterprise transformation system, and design the questionnaire, 96 questionnaires were received, of which 90 valid questionnaires, the recovery rate reached $87.07 \%$, in line with the scientific rationality of statistics. Using the Delphi method to obtain the score of each index, and calculate the index weight by using the methods of weight calculation, as shown in Tables 1, 2. Through formula (1) respectively to calculate the strength of the subsystems of the resources and capabilities, we can obtain the intensity of resource subsystem: $t_{1}=4.2, t_{2}=3.2, t_{3}=3.45, t_{4}=3.13$; the intensity of ability subsystem: $c_{1}=4.5 \quad c_{2}=4.3 \quad c_{3}=3.15$ $c_{4}=4.13$. So that we can get $r=\sqrt{\sum_{i=1}^{4} c_{i}^{2}}=8.107$, and the judgment threshold $s=r / 8=1.013$. Finally, in the formula (2) can be obtained the total matching degree of resource strength and ability level of enterprise transformation system: $L_{T C}=1.612 \sum_{i=1}^{4} t_{i}^{2}=49.58$, so the matching degree of the strength of resources subsystem and ability level of enterprise transformation system: [3.487,5.513], [3.287,5.314], [2.137,4.163], [3.117,5.143].

Analysis of the matching of resources and ability of enterprise K: (1) The total matching analysis: according to the above calculation, $L_{T C}=1.612>\mathrm{s}$, this means that the resource strength and ability level in the process of transformation of $\mathrm{K}$ enterprise does not match, at the same time, because of $\sum_{i=1}^{4} t_{i}^{2}=49.58<r^{2}$, can be determined that the $\mathrm{K}$ enterprise lack of strength of resources in the process of transformation. The overall resources and ability of enterprise transformation in the system of low matching degree, directly affect the enterprise transformation efficiency, hinder the ability of management, innovation ability and the core competitive ability, also indirectly reflects transition speed slow, low efficiency of enterprise K. (2) Component matching analysis: through the matching degree calculation of each subsystem of resources and ability of the K enterprise in the process of transformation can be obtain $t_{1}=4,2 \in[3.49,5.51], \quad t_{2}=3,2 \in[3.29,4.18] \quad\left(t_{2}<3.29\right)$, $t_{3}=3,5 \in[2.14,4.16], t_{4}=3,1 \in[3.12,5.14]$. This shows that for the transformation of enterprise $\mathrm{K}$ the strength of technical resources, economic resources and capital resources of resources system is match with ability level, while for the strength of human resource of resources system is insufficient, and the ability level is not matching. At the same time, further analysis the K enterprise can be found, by Delphi method of the four indicators of human resources subsystem in the score is low, especially in the two indicators of quality of management personnel and staff quality, because these two kinds of index accounted for a larger proportion, the lower the direct impact on the entire the intensity of human resource subsystem, so that it does not match with the ability level. It can be seen reasonable staff training, to promote the overall quality of employees of enterprises to improve the efficiency of the transformation, plays an important role in the successful transformation, and the human resources management is also the key can not be ignored to improve their ability and achieve the transformation and upgrading of enterprise.

\section{CONCLUSION}

In this paper, through the analysis of the relationship between resources and capabilities in enterprise transformation system, we can see that, in enterprise transformation system the resources and ability system is transformed into each other, reciprocal conditions, mutual matching, only the reasonable and effective combination, to achieve high matching degree, the transformation of enterprises in order to achieve the best effect, and promote the development of enterprise. At the same time, through the introduction of the 4 dimensional space 2 points between the concepts of distance calculation model of matching degree of resources and capabilities of enterprise transformation system, so as to calculate the resources and capabilities of enterprise transformation system between the total and component matching degree and state of development, and then found the existing problems of resource management and ability improvement of enterprise transformation system and puts forward the improvement measures in a timely manner, form a good mechanism to solve the problem, to ensure effective enterprise transformation smoothly, achieve the successful transformation of enterprises.

\section{CONFLICT OF INTEREST}

The authors confirm that this article content has no conflict of interest.

\section{ACKNOWLEDGEMENTS}

Declared none.

\section{REFERENCES}

[1] D. Abraham, S. Aier, and R. Winter, "Crossing the line: Overcoming knowledge boundaries in enterprise transformation," Business \& Information Systems Engineering, vol. 57, pp. 3-13, 2015.

[2] G. Plataniotis, S.D. Kinderen and H.A. Proper, "Capturing design rationales in enterprise architecture: a case study," The Practice of Enterprise Modeling, vol. 197, pp. 133-147, 2014.

[3] Y. Liu, and J. Lijima, "Automatic model transformation for enterprise simulation," Advances in Enterprise Engineering, vol. 174, pp. 136-150, 2014.

[4] N. Labusch, F. Koebele, S. Aier, and R. Winter, "The architects' perspective on enterprise transformation: an explorative study," 
Practice-Driven Research on Enterprise Transformation, vol. 151, pp. 106-124, 2013.

[5] E. Proper, K. Gaaloul, F. Harmsen, and S. Wrycza, "Practicedriven research on enterprise transformation," Lecture Notes in Business Information Processing, vol. 69, pp. 525-537, 2010.

[6] X. Wang, X. Song, and J. Yuan, "On matching cover of graphs," Mathematical Programming, vol. 147, pp. 499-518, 2014.

[7] Q. Makins, D. Nagao, and N. Bennett "Enterprise alignment and inertia risks during transformation," Information KnowledgeSystems Management, vol. 11, pp. 151-168, 2012.
[8] Valerie Purchase, G.Parry and J.Mills, "Service enterprise transformation," Complex Engineering Service Systems, vol. 25, pp. 2548, 2011.

[9] M. Bakhshadeh, A. Morais, and A. Caetano, "Ontology transformation of enterprise architecture models," Technological Innovation for Collective Awareness Systems, vol. 423, pp. 55-62, 2014.

[10] J-L. Duanmu, and F M.A. Fai, "Processual analysis of knowledge transfer: From foreign MNEs to Chinese suppliers," International Business Review, vol. 16, pp. 449-473, 2007.

(C) Wang et al.; Licensee Bentham Open.

This is an open access article licensed under the terms of the (https://creativecommons.org/licenses/by/4.0/legalcode), which permits unrestricted, noncommercial use, distribution and reproduction in any medium, provided the work is properly cited 